\title{
A Learning Grid for the multichallenge school ECP
}

\author{
Pierre Michaud and Christian Saguez \\ Ecole Centrale de Paris \\ Grandes Voie des Vignes \\ 92295 CHATENAY-MALABRY Cedex \\ France \\ michaudp@cti.ecp.fr \\ csaguez@ecp.fr
}

\begin{abstract}
The aim of this presentation is to try to define the requirements of a European Learning Grid that would fit best with the challenges and today and future practices of Ecole Centrale Paris. In a first part, after a brief presentation of Ecole Centrale Paris, we describe the actual challenges today practices and the interest of an e-learning GRID. In a second part we describe some potential cases of such system and the associated requirements.
\end{abstract}

Keywords : GRID, Engineering School, lifelong training

\section{Focus}

- identifying learning solutions that can take advantage of GRID technologies ;

- identifying challenges to existing educational and didactical models ;

- identifying and formulating the requirements of a European GRID infrastructure for e-Learning.

\section{ECOLE CENTRALE PARIS CHALLENGES}

Ecole centrale Paris (ECP) is one of the major engineering schools in France. The educational project is based upon an integrated multidisciplinary curriculum which blends scientific and basic technical education, technological training and a concrete introduction to the economic, social and human realities of industry.

The final year $\left(3^{\text {rd }}\right.$ year) is organized along the following lines : an area of concentration to be chosen among 8 science or industry related sectors, a professional track and an end-of-studies project. As example :

- The Applied Mathematics department is devoted to modelling and simulation techniques and data processing methods.

- It has developed an innovative learning methodology using an experience based approach on four topics:

$\begin{array}{ll}\text { - } & \text { Simulation and Virtual Reality } \\ \text { - } \quad \text { Information Processing } \\ \text { - } \quad \text { Mathematics for Finance } \\ \text { Life Sciences. }\end{array}$ 
- The department is also strongly involved in the use of GRID techniques for the simulation of complex systems and $3 \mathrm{D}$ visualisation

- The Information and Telecommunication department is devoted to Business Information Systems, Systems Architecture Telco and Networks, and Advanced Software Development.

- It is very much involved in Data Processing ( including image and voice processing) and Grid Techniques.

Ecole Centrale has developed a powerful Research Centre that includes laboratories and two research teams. The laboratories participate strongly to the students' education in particular by developing original experimental and inductive pedagogic tools. For instance:

- The Applied Mathematics Lab is devoted to the development of methods, technics and mathematical and informatical tools for the design and the analysis of complex systems. It focuses on three main topics :

- $\quad$ numerical methods and optimization technics ;

- mathematical tool for information and image processing, data mining and knowledge management ;

- $\quad$ study of new Information Systems Architecture, mainly of GRID Technologies.

- In the domain of lifelong learning and corporate education, Ecole Centrale Paris develops customized programmes for executives and professional engineers.

- The Educational Project includes a very important international dimension, the TIME Network (European double degree programme) included more than 40 partner universities from the different European countries and a double degree Master's programme exists with Canada, UK, Japan and the USA.

In that context, the main challenges concern the following parts:

- to be able to propose an experimental approach with manipulation of real life problems and use of real tools - especially powerful modelling and simulation softwares ;

- to take into account the rapid evolution of the techniques, which needs real time interactivity and permanent exchanges of information, experience, tools with the international community ;

- to promote and to develop specific tools for the lifelong training - including e-learning technologies ;

- to use the full potential of the information technologies in the educational project ;

- to integrate the new working modes such as concurrent engineering, groupware.

As a result ECP is strongly involved in new advanced learning methodologies for initial engineers education, international masters of engineering and lifelong learning. Most important today's practices are:

- $\quad$ seminars and projects with industrial and academic partners;

- $\quad$ open and flexible approach including external lecturers;

- international and collaborative approach.

In that context, GRID technology is essential to display the information system needed for the programs. In particular, it will permit

- to improve access to tools (modelling and information software, virtual reality tools) otherwise non accessible ;

- to exchange and to create - information- knowledge and experiment tools in the context of a vertical Knowledge data-base ;

- $\quad$ to have access to important processing and computing power ;

- $\quad$ to develop specific training programs based on a collaborative approach especially joint collaborative student projects with European training partners ; 
- to promote e-learning in the case of lifelong training in collaboration with industrial partners.

\section{SOME EXEMPLES OF POTENTIAL PROJECTS}

ECP has developed important relationship with industry (major companies and SME). ECP has already established partnerships with CS Communication and Systems and IBM for the development of GRID technologies. ECP has in mind the enlargement of the sole concept of e-Learning with a focus in the following directions:

- Knowledge Management

This application, very much linked with e-Learning, will handle:

- the ECP (starting from applied mathematics and information and telco groups and applied mathematics lab including later second year projects (such as Celsius) and eventually all or most of ECP);

- $\quad$ the EC intergroup (the other Ecoles Centrales located in Lille, Nantes and Lyon);

- the Time organisation, other groups.

- Autonomic meta computing and simulation

One application we plan to develop concern the analysis, design and management of industrial processes taking into account the new Information Technologies:

- $\quad$ simulation and optimisation of industrial process by using CAD tools and simulation software (simulation in terms of systems of algebraic and differential equations);

- $\quad$ modelling of plants by using CAD tools and visualisation techniques in the context of sustainable development and help for agriculture development and environmental protection for developing countries;

- $\quad$ System Management including tools Supply Chain Management (SCM), Customer Relationship Management (CRM) and Enterprise Resource Planning (ERP);

- biotechnologies by using Datamining techniques, simulation and network in various activities such as drug discovery.

The application will be based on real industrial processes and plants and advanced methods for simulation, optimisation and visualisation of such systems. The use of GRID technologies will permit to have complete interactivity with the different pieces of software in order to develop a learning method using experience based approach, to develop collaborative experiments and to have access to industrial software packages and to the necessary computing power to run them.

- Web Services

- This application will be focused on:

- $\quad$ audio and video services with participants from the IT department and MA/IT Lab but also from the VIA group, an expert group of students in Audio and Video processing;

- a Technological Virtual Institute, consisting of a portal with access to digital library and e-services including computing power, storage, Web Services and e-project space.

- The Virtual Institute Project will be presented and detailed at the $2^{\text {nd }}$ Paris LEGE-WG symposium.

\section{Conclusion}

The projects of Ecole Centrale Paris for the near future using experience based approach, integrating the most recent modelling and simulating tools and based on a very strong international cooperation, will need the most recent information technologies. 
GRID Technology, which gives access to very important storage capacity, transmission and computing power, appears as the best solution to answer to these challenges. Ecole Centrale Paris wishes to participate actively to these experiments by developing specific test-beds. 